\title{
E. coli expression and immunological assessment of expressed recombinant Newcastle disease virus hemagglutinin-neuraminidase protein in chickens
}

\author{
N. SHAHID ${ }^{1}$, A. Q. RAO ${ }^{1}$, A. AHAD ${ }^{1}$, A. GUL ${ }^{1}$, A. LATIF ${ }^{1}$, S. AZAM ${ }^{1}$, M. SHAHID ${ }^{2}$, S. AKHTAR 1 , \\ A. A. SHAHID ${ }^{1}$, T. HUSNAIN ${ }^{1}$
}

\begin{abstract}
${ }^{1}$ Centre of Excellence in Molecular Biology, University of the Punjab, 87-West Canal Bank Road, Lahore-53700, Pakistan; ${ }^{2}$ University of Lahore, Raiwind Road Campus, Lahore, Pakistan
\end{abstract}

Received June 10, 2019; revised November 27, 2019; accepted February 14, 2020

\begin{abstract}
Summary.-Every year, the poultry industry experiences significant economic losses due to epidemics of Newcastle disease virus (NDV). Developing new vaccines by identifying and using the immunogenic hemagglutinin-neuraminidase (HN) protein can protect the poultry industry. In the present study, the full-length HN protein was expressed in Escherichia coli (E. coli) BL21 (DE3) cells, purified via affinity chromatography and detected via western blot analysis using His-specific antibodies. The purified HN protein was further evaluated in chickens to study the immune response against NDV. The successful production of $\mathrm{HN}$-specific IgY proved the activity of the purified HN protein. IgY was present in the serum of immunized chickens. However, the immune response was higher in chickens immunized with purified HN protein along with complete and incomplete adjuvants than in chickens immunized with only the HN protein.
\end{abstract}

Keywords: protein; Newcastle disease virus; poultry; infectious diseases; vaccines

\section{Introduction}

The poultry industry is highly negatively affected by NDV, a member of the genus Avulavirus in the family Paramyxoviridae. NDV is an enveloped virus with a nonsegmented, linear, negative-sense, single-stranded RNA genome (Shahid and Daniell, 2016; Sun et al., 2017). The total NDV genome comprises nearly 15,186 nucleotides (Jin et al., 2017) that encode 6 genes, including two transmembrane glycoproteins, a hemagglutinin-neuraminidase protein $(\mathrm{HN})$ and a fusion protein $(\mathrm{F})$. The NDV envelope includes two types of glycoproteins that are involved in viral infectivity and pathogenicity. Specifically, the F protein is associated with the pathogenicity of the virus.

E-mail: naila.cemb1@gmail.com; phone: +923014710358.

Abbreviations: ELISA(s) = enzyme-linked immunosorbent assay(s); HN = hemagglutinin-neuraminidase; NDV = Newcastle disease virus
The HN protein is a versatile molecule with distinctive actions i.e., fusion assistance, receptor binding and neuraminidase activity (NA). The two binding sites of the HN globular head (sites 1 and 2) are responsible for its neuraminidase and fusion activities, respectively. The stalk region promotes fusion by interacting with the F protein, which is responsible for virion penetration into the cell surface (Ewies et al., 2017; Jin et al., 2017; Dey et al., 2019). The HN protein possesses neuraminidase activity; it binds sialic-acid-containing receptors (hemagglutination) on host cells. These receptors on the host cell cleave the sialic acid molecules and release the resultant viral particles. The HN protein also strongly promotes NDV virulence and tissue tropism. The high antigenic property and the ability to stimulate antibody production by inducing host's protective immune response make the HN protein a suitable target antigen for the production of recombinant vaccines against NDV (Habib et al., 2015). Moreover, the length of the HN protein is very critical to its biological 
activities, as a 571-aa HN protein has been reported only in highly virulent strains; a 577-aa HN protein exists both in avirulent and virulent strains, whereas a larger $\mathrm{HN}$ protein of 616 aa has been reported only in non-virulent strains (Römer-Oberdörfer et al., 2003).

The poultry industry plays a vital role in strengthening the economy, especially in developing countries. In Pakistan, economic losses due to NDV have reached up to US \$106.5 million, or 10 billion Pakistan rupees (PKR), in the last decade (Grace, 2014). The morbidity and mortality rates are up to $100 \%$ for severe forms of the disease (Alexander et al., 1997). Therefore, epidemiological studies have been conducted to control NDV outbreaks.

A number of studies have aimed to design NDV vaccines that are more efficient than conventional live attenuated and inactivated vaccines (Shahid and Daniell, 2016); these vaccines include DNA vaccines (Sawant et al., 2011), reverse-genetics-generated recombinant vaccines (Zhao et al., 2014; Wang et al., 2015), subunit vaccines (Kumar et al., 2011; Esaki et al., 2013) and vector vaccines (Li et al., 2014). Early diagnosis is critical to effectively control this epidemic disease. Hemagglutination inhibition (HI) tests and enzyme-linked immunosorbent assays (ELISAs) are effective for detecting anti-NDV antibodies. However, commercially available ELISA kits with pre-coated antigens are very expensive, particularly in developing countries. The use of purified recombinant NDV proteins, i.e., NP or HN, in ELISAs is considered an alternative solution to this problem. These proteins can be successfully expressed in E. coli and further used in indirect ELISAs for anti-NDV antibody quantification (Yusoff and Tan, 2001; Silva et al., 2014).

In the present study, an attempt was made to characterize the HN protein under lab conditions and to further determine its efficacy in the production of antibodies against NDV in chickens.

\section{Materials and Methods}

Viral strain collection and propagation. The virulent NDV strain was obtained from the Veterinary Research Institute, Lahore, Pakistan (Acc. No. FJ430159.1). Viral propagation and dilution were conducted in a Biosafety Level III laboratory (CEMB, Lahore, Pakistan).

Amplification and sequence confirmation of the HN gene. RNA was isolated from the NDV strain using the TRIzol-based method. The RNA template, random hexamer primers and a Revert Aid first-strand cDNA synthesis kit (Thermo Scientific, K1622) were used for reverse transcription PCR (RT-PCR) according to the manufacturer's protocol. The NDV HN gene was amplified from cDNA with forward primer 5'-ATGGACAGCG CATGTAGCCAAGTT-3' and reverse primer 5'-TTAAACCCCAC
CATCCTTGAG-3' under the following PCR conditions: initial denaturation at $95^{\circ} \mathrm{C}$ for $5 \mathrm{~min} ; 35$ cycles of $95^{\circ} \mathrm{C}$ for $1 \mathrm{~min}, 60^{\circ} \mathrm{C}$ for $1 \mathrm{~min}$ and $72^{\circ} \mathrm{C}$ for $1 \mathrm{~min}$; and a final extension at $72^{\circ} \mathrm{C}$ for $15 \mathrm{~min}$. The amplified fragment was visualized via $1 \%$ agarose gel electrophoresis. The amplified HN gene fragment was cloned into the pCR2.1 vector according to the manufacturer's protocol (Thermo Fisher TA cloning kit), and the sequence was confirmed by Macrogen Advanced Genomics, Korea.

Construction of E. coli expression vector and expression studies of recombinant $\mathrm{HN}$. The $\mathrm{pET} 30 \mathrm{a}$ expression vector, featuring a T7 promoter, N/C-terminal His-tag sequence, T7 terminator and Lac operator, was used, and the HN gene was ligated between the EcoRI and HindIII restriction sites. The HN-pET30a ligation product was transformed into TOP10 competent E. coli cells and spread on Luria Bertani plates containing kanamycin. Positive clones were screened via EcoRI and HindIII restriction digestion. BL21 (DE3) cells transformed with pET30a-HN were grown overnight at $37^{\circ} \mathrm{C}$ in LB media containing antibiotics. The primary culture was used to inoculate fresh media (1:10 $\mathrm{v} / \mathrm{v}$ ), which was then incubated for $3 \mathrm{~h}$ on a shaker. At an optical density of 0.6-0.8, expression of the recombinant protein was induced with $1 \mathrm{mM}$ isopropyl B-D-1-thiogalactopyranoside (IPTG) and incubated at $30^{\circ} \mathrm{C}$ for $18 \mathrm{~h}$. The cells were pelleted by centrifugation at $4,000 \mathrm{xg}$ for $15 \mathrm{~min}$ at $4^{\circ} \mathrm{C}$. Then, the cells were washed twice with $10 \mathrm{ml}$ of $1 \mathrm{x}$ PBS and resuspended in lysis buffer (1x PBS, 500 mM NaCl, 1\% Triton X-100, 6\% glucose, $1 \mathrm{mM}$ phenyl methane sulphonyl fluoride) for sonication. The sonication conditions were a continuous pulse at $20 \mathrm{kHz}$ for 30 s on ice. To completely lyse the cells, the process was repeated $15-20$ times for $60 \mathrm{~s}$. The lysed cells were then centrifuged at $16,000 \mathrm{x} g$ for $30 \mathrm{~min}$, and the supernatant was stored at $4^{\circ} \mathrm{C}$. The crude protein from $E$. coli extract was subjected to purification through affinity column chromatography in a Kelvinator chromatography refrigerator. Two column volumes of binding buffer containing $500 \mathrm{mM} \mathrm{NaCl}$ and $20 \mathrm{mM}$ sodium phosphate buffer, pH 7.4, were used to equilibrate the Sepharose adsorbent. A linear flow rate of $150 \mathrm{~cm} / \mathrm{h}$ was maintained to load the protein onto the column. The column was washed with 2 column volumes of wash buffer 1 (binding buffer and $20 \mathrm{mM}$ imidazole, pH 7.4) and wash buffer 2 (binding buffer and $40 \mathrm{mM}$ imidazole, $\mathrm{pH} 7.4$ ) to successfully remove any unbound proteins and contaminating solutes. The recombinant HN protein was eluted from the column in a step-wise elution with five increasing concentrations of imidazole from $70 \mathrm{mM}$ to $150 \mathrm{mM}$. Five 1-ml fractions from each elution concentration were collected, and the protein concentration was quantified using the Bradford assay. A total of $5 \mu \mathrm{g}$ of protein was loaded into each well, and the protein purity was visualized via $12 \%$ dodecyl sulfate- polyacrylamide gel electrophoresis (SDS-PAGE) following the procedure of Laemmli (Laemmli, 1970). Coomassie brilliant blue (R 250; cat. No. 20278) staining was used to visualize the protein bands. For western blot, the protein was carefully transferred from the gel to a polyvinylidene fluoride (PVDF) membrane(Mil- 
(a)

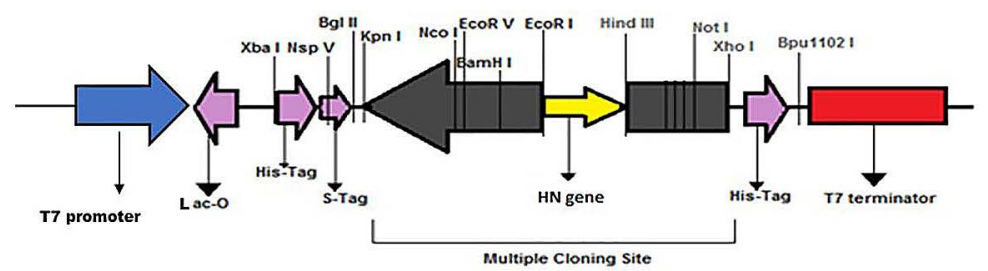

(b)

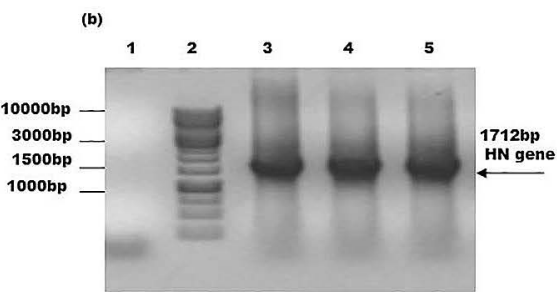

(c)

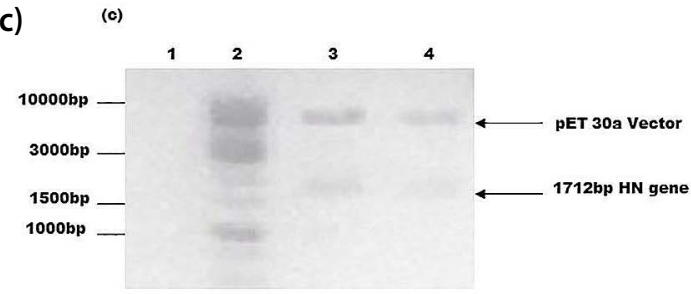

Fig. 1

Confirmation of the HN gene in the pET30a vector

(a) The presence of the HN gene in PET30a was confirmed via PCR. Lane 1 is a negative control (amplification without template); Lane 2 shows a 1-kb ladder, and lanes 3-5 show transformed clones. (b) The presence of the HN gene in the pET30a vector was confirmed via restriction digestion. Lane 2 shows a 1-kb ladder, and Lanes 3 and 4 show restriction-digested pET-HN clones.

lipore, USA) according to Chong et al. (2009). Recombinant HN protein was detected with rabbit polyclonal anti-His antibodies according to the manufacturer's guidelines (1:5,000 dilution; cat. No. sc-804; Santa Cruz). The 69-kDa recombinant HN protein was detected using alkaline phosphatase-conjugated 1-bromo3-chloro-3-indolyl phosphate/nitro blue tetrazolium substrate.

Immunogenicity assay. The levels of functional antibodies in the sera of immunized and control animals were assessed via ELISA as described previously (Berinstein et al., 2005; Quan et al., 2007; Silva et al., 2014). Purified protein from BL21 (DE3) E. coli expressing the NDV HN protein was used as an antigen to promote the immune response. The immunogenicity assay was performed on ten-day-old specific pathogen-free (SPF) chickens purchased from hatcheries and reared in an animal facility. The chickens were separated into three groups, groups 1, 2 and 3, with 5 birds per group. The chickens in each group were allowed to feed ad libitum. Group 1 was used as a negative control. The chickens in group 2 were immunized with $20 \mu$ g of purified $\mathrm{HN}$ protein via subcutaneous injection at intervals of $0,10,20,30,40$, 50 and 60 days. Group 3 was immunized with $20 \mu \mathrm{g}$ of purified HN protein along with $0.2 \mathrm{mg} / \mathrm{ml}$ of complete Freund's adjuvant (CFA) and booster dose of incomplete Freund's adjuvant after 15 days interval by a subcutaneous injection. Blood was collected every ten days, and serum was isolated by incubating the samples at $25^{\circ} \mathrm{C}$ for $45 \mathrm{~min}$, followed by centrifuging at $4^{\circ} \mathrm{C}$ $(4,000 \mathrm{x} \mathrm{g})$ for $15 \mathrm{~min}$. The collected serum from each sample was evaluated for the presence of HN-specific IgY for up to 60 days using AP-conjugated goat anti-chicken IgY (ab 6877). To determine the IgY level in each serum sample, the absorbance values were recorded at $450 \mathrm{~nm}$.
Statistical analysis. All data were analyzed using analysis of variance in a statistical analysis program (GraphPad Prism version 7) for Windows. To determine significant differences, the means of all treatments were compared using Tukey's multiple comparison test. Differences were considered significant when $\mathrm{P}<0.05$.

\section{Results}

Construction of an expression vector harboring the HN gene

The full-length 1712-bp HN gene was amplified from cDNA and confirmed through PCR (Fig. 1a). The specific 1712-bp HN fragment was similar to that of type III Mukteswar, a mesogenic NDV strain with accession number FJ430159.1. The resultant full-length $\mathrm{HN}$ gene was cloned into the pET30a protein expression vector. The full-length HN gene was confirmed to be in the pET30a protein expression vector through digestion, which generated a 1712-bp fragment (Fig. 1b).

Expression and purification of recombinant $\mathrm{HN}$ protein in E. coli

BL21 (DE3) E. coli cells were transformed with the recombinant $\mathrm{pET} 30$ a vector containing the cloned $\mathrm{HN}$ gene. Upon induction with $1 \mathrm{mM}$ IPTG, high protein expression 
(a)

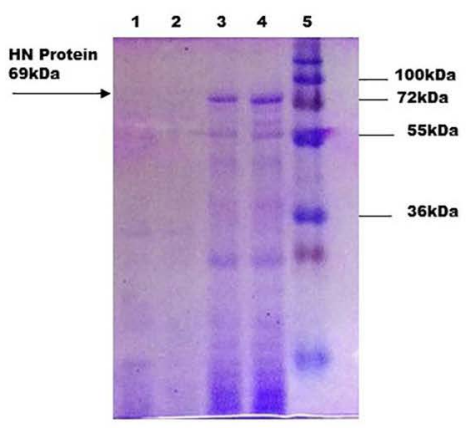

(b)

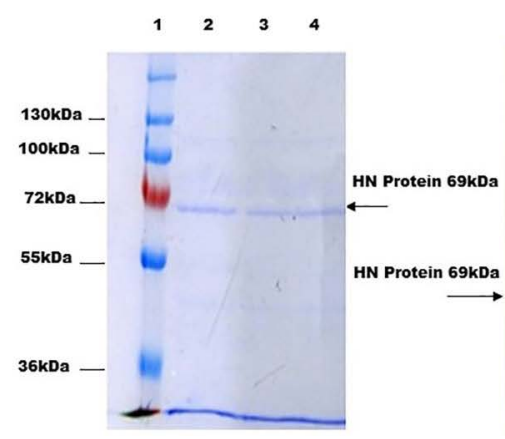

Fig. 2 (c)

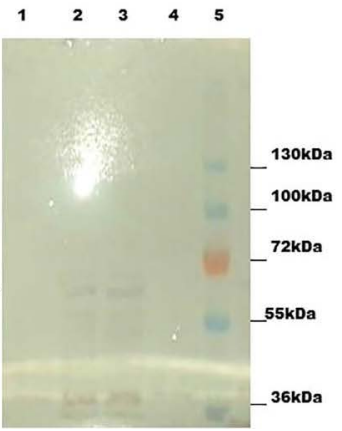

Expression studies of the HN protein

(a) The expression of the HN protein was confirmed via SDS-PAGE. Lane 1 and 2 show a negative control (untransformed Rosetta cells), whereas Lanes 3 and 4 show Rosetta cells transformed with the HN gene, and Lane 5 contains a pre-stained protein marker (Fermentas) (b) The HN protein was purified via IMAC. Lane 1 is a pre-stained protein marker (Fermentas), and Lanes 2-4 show purified HN protein (c) The expression of the HN protein was confirmed via western blot analysis. Lane 1 shows a negative control (untransformed Rosetta cells); whereas Lanes 2-4 show Rosetta cells transformed with the HN gene, and Lane 5 contains a pre-stained protein marker (Fermentas).

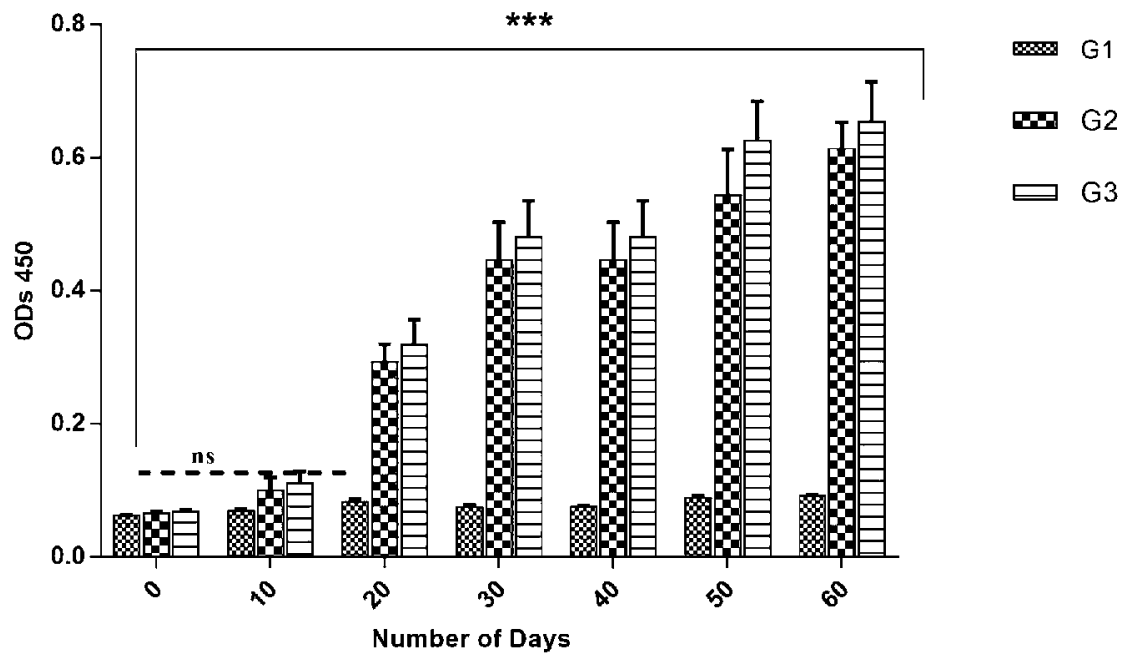

Fig. 3

Induction of the immune response against the HN protein

$\mathrm{HN}$-specific serum IgY immune responses in chickens immunized with the HN protein (group 2) and chickens immunized with HN protein and boosted with complete and incomplete adjuvant (group 3) The chicken in group 3 showed a slightly greater humoral response with each booster than did chickens in group 2. No immunogenic response was observed in control group. Data shown are average \pm SD $(\mathrm{n}=5$ /group). The significance of the data is determined by one-way ANOVA and $\mathrm{p}<0.001$ is indicated by “***” above bars, whereas "ns" represents non-significant.

was observed after $5-7 \mathrm{~h}$ at $25^{\circ} \mathrm{C}$. SDS-PAGE and Coomassie blue staining of the obtained soluble fractions revealed a sharp band of $69 \mathrm{kDa}$ (HN protein) (Fig. 2a). The expressed His-fused protein was purified via immobilized metal affinity chromatography (IMAC) with $100 \mathrm{mM}$ imidazole, which resulted into a single $69-\mathrm{kDa}$ band corresponding to the HN protein (Fig. $2 \mathrm{~b}$ ). The average yield of purified $\mathrm{HN}$ protein was quantified by referencing a known con- centration of BSA (standard) (Bradford, 1976). The average $\mathrm{HN}$ protein concentration was $34.1 \mathrm{ng} / \mu \mathrm{l}$. The purified protein was electrophoretically transferred onto a PVDF membrane (Millipore, USA), and the $69-\mathrm{kDa}$ HN protein was detected using polyclonal anti-His AP-conjugated antibodies (Santa Cruz, UK). Color development with BCIP/ NBT substrate confirmed the presence of the 69-kDa HN protein (Fig. 2c). 


\section{Immunogenicity assay}

The serum IgY level in immunized chickens was examined to determine the immune response after induction with purified HN protein. The antibody levels peaked 50-60 days post-vaccination. Chickens immunized with $\mathrm{HN}$ protein produced significantly higher antibody titers than did those in the negative control group. Chickens immunized with HN protein and boosted with complete and incomplete adjuvants showed slightly higher antibody titers against the HN protein than did those in group 2, which received only purified HN protein (Fig. 3).

\section{Discussion}

The control of NDV through vaccines is challenging due to various factors, such as genetic variation among endemic viral strains and mismatching of the NDV vaccine used in the field, causing incomplete protection against the disease and a failure of the vaccine to induce immunity against particular viral strains (Iram et al., 2014; Shabbir et al., 2016; Shahid et al., 2017).

In this study, we described the immunogenic properties of recombinant NDV HN protein. The HN protein is the most important antigen that can induce a strong immune response. The HN protein is a capsid protein that attaches itself firmly to the viral membrane, thus making it very difficult to isolate and purify from infected cells (Shahid et al., 2015). Immunization with recombinant HN protein has been attempted many times to study protective immune responses in chickens (Boursnell et al., 1990; Edbauer et al., 1990; Sun et al., 2008; Su et al., 2011). In the current study, an attempt was made to evaluate the immune response against recombinant $\mathrm{HN}$ in chickens at different time intervals; the stimulation of the immune response indicated that the recombinant HN protein had properly folded. The effectiveness of the recombinant $\mathrm{HN}$ protein obtained here still needs to be compared to the ND vaccines used in the field, which are produced in embryonated chicken eggs. We used only purified $\mathrm{HN}$ antigen at a concentration of $20 \mu \mathrm{g} /$ dose in chickens. Our results indicated that $20 \mu \mathrm{g}$ of $\mathrm{HN}$ protein was safe for the chickens and elicited a significant immune response that was stable for up to 50 days, but an immune response did not occur in the negative control group. The slightly enhanced immune responses in group 3 (chickens immunized with HN protein and boosted with complete and incomplete adjuvant) might be due to boosting with adjuvant (Shen et al., 2013). The comparable immune responses between the two treatments [groups 2 (chickens immunized with HN protein) and group 3 (chickens immunized with $\mathrm{HN}$ protein and boosted with complete and incomplete adjuvant] have practical significance because adjuvant use has not been endorsed for human vaccines (Aguilar-Yáñez et al., 2010; Alving et al. ,2012)

Even if the recombinant HN obtained in this study produces immunity comparable to that of ND vaccines used in the field, it is more appealing, as the recombinant technology described here can produce at least 1000 more doses than can egg-based vaccines in a similar time interval. This technology can produce 2.2 million doses per day in a conventional 1,000 L bioreactor, which makes it better than conventional egg-based vaccines. Moreover, a bacterial-expression-based vaccine production system is a cost-effective solution for most endemic and pandemic veterinary diseases (Song et al., 2008; Aguilar-Yáñez et al., 2010).

\section{Conclusion}

We conclude that the recombinant HN protein produced in $E$. coli could potentially replace commercial egg-based vaccines. A number of potentially active recombinant vaccines against veterinary diseases have been produced in E. coli (Shen et al., 2008; Chiu et al., 2009). As an example, recombinant HA63-286 against avian influenza produced in $E$. coli was immunogenic, produced neutralizing antibodies and showed protection in a ferret model (Aguilar-Yáñez et al., 2010). Similarly, a recombinant 60-kDa HA protein from $\mathrm{H} 5 \mathrm{~N} 1$ against avian influenza produced in $E$. coli yielded a protective immune response in mice (Shen et al., 2008).

The recombinant HN protein obtained here has a potential for use as a diagnostic tool in laboratories to determine the efficiency of routinely used vaccines against NDV (Nallaiyan et al., 2010). The current study shows that the NDV HN protein expressed in E. coli can be used as part of a generally low-cost and high-capacity platform for the poultry industry, which has low profit margins, during disease outbreaks. These attributes will also prove valuable in the development of more immunogenic vaccines for NDV by targeting more-immunogenic epitopes. Unfortunately, the laboratory facilities required for neutralization assays and for testing the ability of the vaccine to protect chickens from NDV infection are not available at our institution. Therefore, we were unable to perform these experiments. Collaborative work is in progress to evaluate the efficacy of the recombinant $\mathrm{HN}$ protein in protecting chickens against NDV infection.

Acknowledgments. We acknowledge the Higher Education Commission, Pakistan, for Ph.D. student financial support (No. 112-26729-2Bm1-396) to continue this study. 


\section{References}

Aguilar-Yáñez JM, Portillo-Lara R, Mendoza-Ochoa GI, GarcíaEchauri SA, López-Pacheco F, Bulnes-Abundis D, Salgado-Gallegos J, Lara-Mayorga IM, Webb-Vargas Y, León-Angel FO, Rivero-Aranda RE (2010): An influenza A/H1N1/2009 hemagglutinin vaccine produced in Escherichia coli. PLoS One 5, 7, el1694. https://doi. org/10.1371/journal.pone.0011694

Alexander DJ, Manvell RJ, Lowings JP, Frost KM, Collins MS, Russell PH, Smith JE (1997): Antigenic diversity and similarities detected in avian paramyxovirus type 1 (Newcastle disease virus) isolates using monoclonal antibodies. Avian. Pathol. 26, 399-418. https://doi. org/10.1080/03079459708419222

Alving CR, Peachman KK, Rao M, Reed SG (2012): Adjuvants for human vaccines. Curr. Opin. Immunol. 24, 310-315. https://doi.org/10.1016/i.coi.2012.03.008

Berinstein A, Vazquez-Rovere C, Asurmendi S, Gómez E, Zanetti F, Zabal O, Tozzini A, Grand DC, Taboga O, Calamante G, Barrios H (2005): Mucosal and systemic immunization elicited by Newcastle disease virus (NDV) transgenic plants as antigens. Vaccine 23, 5583-5589. https://doi. org/10.1016/i.vaccine.2005.06.033

Boursnell ME, Green PF, Samson AC, Campbell JI, Deuter A, Peters RW, Millar NS, Emmerson PT, Binns MM (1990): A recombinant fowlpox virus expressing the hemagglutinin-neuraminidase gene of Newcastle disease virus (NDV) protects chickens against challenge NDV. Virology 178, 297-300. https://doi.org/10.1016/00426822(90)90408-J

Bradford MM (1976): A rapid and sensitive method for the quantitation of microgram quantities of protein utilizing the principle of protein-dye binding. Anal. Biochem.72, 248-254. https://doi.org/10.1016/0003-2697(76)90527-3

Chiu FF, Venkatesan N, Wu CR, Chou AH, Chen HW, Lian SP, Liu SJ, Huang CC, Lian WC, Chong P, Leng CH (2009): Immunological study of HAl domain of hemagglutinin of influenza $\mathrm{H} 5 \mathrm{~N} 1$ virus. Biochem. Biophys. Res. Commun. 383, 27-31. https://doi.org/10.1016/i. bbrc.2009.03.106

Chong FC, Tan WS, Biak DR, Ling TC, Tey BT. Purification of histidine-tagged nucleocapsid protein of Nipah virus using immobilized metal affinity chromatography (2009): J. Chromatogr. B. Analyt. Technol. Biomed. Life Sci. 877, 1561-1567. https://doi.org/10.1016/j. jchromb.2009.03.048

Dey S, Pathak DC, Debnath A, Ramamurthy N, D'Silva AL, Chellappa MM (2019): Newcastle Disease Virus. In Malik Y, Singh R, Yadav M (Eds): Recent Advances in Animal Virology. Springer, Singapore, 321-328.

Edbauer C, Weinberg R, Taylor J, Rey-Senelonge A, Bouquet JF, Desmettre P, Paoletti E (1990): Protection of chickens with a recombinant fowlpox virus expressing the Newcastle disease virus hemagglutinin-neuraminidase gene. Virology 179, 901-904. https://doi. org/10.1016/0042-6822(90)90165-N
Esaki M, Godoy A, Rosenberger JK, Rosenberger SC, Gardin Y, Yasuda A, Dorsey KM (2013): Protection and antibody response caused by turkey herpesvirus vector newcastle disease vaccine. Avian Dis. 57, 750-755. https:// doi.org/10.1637/10540-032613-Reg.1

Ewies SS, Ali A, Tamam SM, Madbouly HM (2017): Molecular characterization of Newcastle disease virus (genotype VII) from broiler chickens in Egypt. Beni-Suef univ. J. Basic Appl. Sci. 6, 232-237. https://doi.org/10.1016/i. bjbas.2017.04.004

Grace D (2014): The business case for one health. Onderstepoort J.Vet. Res. 81,1-6.https://doi.org/10.4102/ojvr.v81i2.725

Habib H, Rehmani S, Mukhtar N, Bibi T, Wajid A (2015): Biological and molecular characterization of newcastle disease virus through haemagglutinin-neuraminidase gene isolated from lahore district. J. Inf. Mol. Biol. 3, 28-33. https://doi.org/10.14737/journal.jimb/2015/3.2.28.33

Iram N, Shah MS, Ismat F, Habib M, Iqbal M, Hasnain SS, Rahman M (2014): Heterologous expression, characterization and evaluation of the matrix protein from newcastle disease virus as a target for antiviral therapies. Appl. Microbiol. Biotechnol.98,1691-1701. https://doi. org/10.1007/s00253-013-5043-2

Jin JH, Cheng JL, He ZR, Ren YC, Yu XH, Song Y, Yang HM, Yang YL, Liu T, Zhang GZ (2017): Different Origins of Newcastle Disease Virus Hemagglutinin-Neuraminidase Protein Modulate the Replication Efficiency and Pathogenicity of the Virus. Front. Microbiol. 8, 1607. https://doi.org/10.3389/fmicb.2017.01607

Kumar S, Nayak B, Collins PL, Samal SK (2011): Evaluation of the newcastle disease virus $\mathrm{F}$ and $\mathrm{HN}$ proteins in protective immunity by using a recombinant avian paramyxovirus type 3 vector in chickens. J. Virol. 85, 6521-6534. https://doi.org/10.1128/JVI.00367-11

Laemmli UK (1970): Cleavage of structural proteins during the assembly of the head of bacteriophage $t 4$. Nature 227, 680-685. https://doi.org/10.1038/227680a0

Lee G, Na YJ, Yang BG, Choi JP, Seo YB, Hong CP, Yun CH, Kim DH, Sohn EJ, Kim JH, Sung YC (2015): Oral immunization of haemaggulutinin $\mathrm{H} 5$ expressed in plant endoplasmic reticulum with adjuvant saponin protects mice against highly pathogenic avian influenza A virus infection. Plant Biotechnol. J. 13, 62-72. https://doi. org/10.1111/pbi.12235

Li K, Gao L, Gao H, Qi X, Gao Y, Qin L, Wang Y, Wang X (2014): Recombinant infectious bursal disease virus expressing newcastle disease virus (NDV) neutralizing epitope confers partial protection against virulent NDV challenge in chickens. Antivir. Res. 101, 1-11. https://doi. org/10.1016/j.antiviral.2013.10.016

Nallaiyan S, Abbadorai RS, Sundaramoorthy S, Nelson J, Sanyasi SV (2012): Production and application of recombinant haemagglutinin neuraminidase of Newcastle disease virus. Asian Pac. J. Trop. Med. 3, 629-632. https://doi. org/10.1016/S1995-7645(10)60152-6

Quan FS, Huang C, Compans RW, Kang SM (2007): Virus-like particle vaccine induces protective immunity against 
homologous and heterologous strains of influenza virus. J. Virol. 81, 3514-3524. https://doi.org/10.1128/ JVI.02052-06

Römer-Oberdörfer A, Werner O, Veits J, Mebatsion T, Mettenleiter TC (2003): Contribution of the length of the hn protein and the sequence of the $f$ protein cleavage site to newcastle disease virus pathogenicity. J. Gen. Virol. 84, 3121-3129. https://doi.org/10.1099/vir.0.19416-0

Sawant PM, Verma PC, Subudhi PK, Chaturvedi U, Singh M, Kumar R, Tiwari AK (2011): Immunomodulation of bivalent newcastle disease DNA vaccine induced immune response by co-delivery of chicken IFN- $\gamma$ and IL-4 genes. Vet. Immunol. Immunopathol. 144, 36-44. https://doi.org/10.1016/i.vetimm.2011.07.006

Shabbir MZ, Akhtar S, Tang Y, Yaqub T, Ahmad A, Mustafa G, Alam MA, Santhakumar D, Nair V, Munir M (2016): Infectivity of wild bird-origin avian paramyxovirus serotype 1 and vaccine effectiveness in chickens. J. Gen. Virol. 97, 3161-3173. https://doi.org/10.1099/ igv.0.000618

Shahid N, Daniell H (2016): Plant-based oral vaccines against zoonotic and non-zoonotic diseases. Plant Biotechnol. J. 14, 2079-2099. https://doi.org/10.1111/pbi.12604

Shahid N, Rao AQ, Kristen PE, Ali MA, Tabassum B, Umar S, Tahir S, Latif A, Ahad A, Shahid AA, Husnain T (2017): A concise review of poultry vaccination and future implementation of plant-based vaccines. World Poultry Sci. J. 73, 471-482. https://doi.org/10.1017/ $\underline{\mathrm{S} 0043933917000484}$

Shahid N, Tahir S, Rao AQ, Hassan S, Khan A, Latif A, Khan MA, Tabassum B, Shahid AA, Zafar AU (2015): Escherichia coli expression of ndv fusion protein gene and determination of its antigenic epitopes. Biologia 70,1553-1564, https://doi.org/10.1515/biolog-2015-0191

Shen H, Xue C, Lv L, Wang W, Liu Q, Liu K, Chen X, Zheng J, Li X, Cao $Y$ (2013): Assembly and immunological properties of a bivalent virus-like particle (VLP) for avian influenza and Newcastle disease. Virus Res. 178, 430-436. https://doi.org/10.1016/i.virusres.2013.09.009

Shen S, Mahadevappa G, Oh HL, Wee BY, Choi YW, Hwang LA, Lim SG, Hong W, Lal SK, Tan YJ (2008): Comparing the antibody responses against recombinant hemagglutinin proteins of avian influenza A (H5N1) virus expressed in insect cells and bacteria. J. Med. Virol.80, 1972-1983. https://doi.org/10.1002/jmv.21298
Silva KR, Goncalves MCM, Oliveira E, Fernando FS, Montassier M, Fernandes CC, Tamanine M, Borzi MM, Santos R, Mendonca A (2014): Cloning and expression of the nucleoprotein gene (NP) of newcastle disease virus (NDV) in escherichia coli for immunodiagnosis application. Int. J. Poult. Sci. 13, 473-479. https://doi.org/10.3923/ ijps.2014.473.479

Song L, Nakaar V, Kavita U, Price A, Huleatt J, Tang J, Jacobs A, Liu G, Huang Y, Desai P (2008): Efficacious recombinant influenza vaccines produced by high yield bacterial expression: A solution to global pandemic and seasonal needs. PLoS One 3, e2257. https://doi.org/10.1371/ journal.pone.0002257

Su BS, Shen PC, Hung LH, Huang JP, Yin HS, Lee LH (2011): Potentiation of cell-mediated immune responses against recombinant hn protein of newcastle disease virus by recombinant chicken IL-18. Vet. Immunol. Immunopathol.141,283-292. https://doi.org/10.1016/j. vetimm.2011.03.018

Sun HL, Wang YF, Tong GZ, Zhang PJ, Miao DY, Zhi HD, Wang M, Wang M (2008): Protection of chickens from Newcastle disease and infectious laryngotracheitis with a recombinant fowlpox virus co-expressing the $\mathrm{F}, \mathrm{HN}$ genes of Newcastle disease virus and gB gene of infectious laryngotracheitis virus. Avian. Dis. 52, 111-117. https:// doi.org/10.1637/7998-041807-Reg

Sun J, Han Z, Qi T, Zhao R, Liu S (2017): Chicken galectin-1b inhibits newcastle disease virus adsorption and replication through binding to hemagglutinin-neuraminidase (HN) glycoprotein. J. Biol. Chem. 292, 20141-20161. https://doi.org/10.1074/jbc.M116.772897

Wang J, Wang C, Feng N, Wang H, Zheng X, Yang S, Gao Y, Xia $X$, Yin R, Liu X, Hu S (2015). Development of a reverse genetics system based on RNA polymerase II for Newcastle disease virus genotype VII. Virus Genes. 50, 152-155. https://doi.org/10.1007/s11262-014-1137-x

Yusoff K, Tan WS (2001): Newcastle disease virus: Macromolecules and opportunities. Avian. Pathol. 30, 439-455. https://doi.org/10.1080/03079450120078626

Zhao W, Spatz S, Zhang Z, Wen G, Garcia M, Zsak L, Yu Q (2014): Newcastle disease virus (NDV) recombinants expressing infectious laryngotracheitis virus (ILTV) glycoproteins gb and gd protect chickens against iltv and ndv challenges. J.Virol. 88, 8397-8406. https://doi. org/10.1128/JVI.01321-14 